\title{
Entre o popular e o erudito, "a civilização no Brasil começou pelos pés"'
}

\author{
Vera Aragão de Souza Sanchez \\ Doutoranda em Memória Social (Universidade Federal do Estado do Rio de Janeiro) \\ Rio de Janeiro, Brasil \\ varagao@superig.com.br
}

Resumo O senso comum considera o ballet uma arte importada, sem nada a ver com a nossa tradição cultural, enquanto o carnaval seria a nossa manifestação popular mais significativa. Com base nessa crença, este trabalho pretende mostrar que esses dois gêneros culturais, assim como algumas danças folclóricas brasileiras, partilham da mesma origem. Observamos como as composições coreográficas dos ballets podem apresentar elementos ditos populares, assim como, no carnaval, a sistematização coreográfica é cada vez mais praticada nas escolas de samba, campo no qual profissionais oriundos das artes chamadas de eruditas imprimem princípios acadêmicos à arte popular. Assim, tomamos como ponto de partida o conceito da "tradição inventada", proposto por Eric Hobsbawm e Terence Ranger, para investigar de que forma ocorrem as (re) apropriações entre essas três expressões artísticas e como se dá a convivência entre a dança erudita e a dança popular nos dias de hoje.

Palavras-chave: Ballet, carnaval, danças folclóricas , cultura, tradição inventada.

\section{Introdução}

É Senso comum considerar o ballet uma arte importada, distante de nossa tradição cultural, enquanto o carnaval é sempre mencionado como a nossa manifestação popular mais significativa e autêntica. Mas os elementos que formaram o ballet e o carnaval vêm sendo retomados e reapropriados ao longo do tempo, imbricando entre si princípios apolíneos e dionisíacos, conforme sustentado por Nietzsche. Entretanto, ao longo do tempo, é possível observar como cada vez mais as composições coreográficas dos ballets apresentam elementos ditos populares, do mesmo modo que, no carnaval, a sistematização coreográfica é cada vez mais praticada nas escolas de samba, campo onde profissionais oriundos das chamadas artes eruditas imprimem princípios acadêmicos à arte popular.

Inicialmente, tomemos como base o sentido de tradição dado por Hobsbawm e Ranger (2002, p.11), ou melhor, o conceito de "tradição inventada", essencialmente o processo de formalização, ritualização e cristalização de hábitos construídos no passado, transmitidos por meio da repetição. Fixando-se no imaginário da sociedade, as tradições não necessariamente existiram desde os primeiros tempos; podem ter sido realmente fabricadas, ou ser resultado de práticas às vezes recentes, mas estabelecidas em curto espaço de tempo. Desse modo, "tradição inventada" é entendida como

1. Enunciado extraído de matéria jornalística do Correio Mercantil de 14 de outubro de 1849, p. 1. 
um conjunto de práticas, normalmente reguladas por regras tácitas ou abertamente aceitas; tais práticas, de natureza ritual ou simbólica, visam inculcar certos valores e normas de comportamento através da repetição, o que implica, automaticamente, uma continuidade em relação ao passado. Aliás, sempre que possível, tenta-se estabelecer uma continuidade com um passado histórico apropriado. (Hobsbawm; Ranger, 2002, p. 9)

Frequentemente, também a identidade nacional imagina-se original, "na ideia de um povo ou folk puro, mas nas realidades do desenvolvimento nacional, é raramente esse povo (folk) primordial que persiste ou que exercita o poder", como determina Hall (2005, p. 55-56). Nessa linha de pensamento, consideramos a cultura nacional constituída não apenas de instituições culturais, mas de um discurso histórico normativo que, ao produzir sentido e identificações, automaticamente constrói identidades, enfatizando as origens, dando continuidade à tradição ou inventando tradições. Segundo Hobsbawm e Ranger (2002, p. 10),

na medida em que há referência a um passado histórico, as tradições "inventadas" caracterizam-se por estabelecer com ele uma continuidade bastante artificial. Em poucas palavras, elas são reações a situações novas que ou assumem a forma de referência a situações anteriores, ou estabelecem seu próprio passado através da repetição quase que obrigatória.

Sob esse aspecto, voltamos a Hobsbawm e Ranger para diferenciar tradição e costumes. Para eles, as tradições - inventadas ou não - caracterizam-se pela invariabilidade imposta pela repetição, embora possam evoluir ou adquirir outras características ao longo do tempo, reinventando-se, enquanto os costumes passam de geração a geração. "Costume é o que fazem os juízes" - dizem eles - "tradição é a peruca, a toga e outros acessórios e rituais formais que cercam a substância” (p. 10).

Pode-se observar uma nítida diferença entre as práticas antigas e as inventadas. As primeiras eram práticas sociais específicas e altamente coercivas, enquanto as últimas tendiam a ser bastante gerais e vagas quanto à natureza dos valores, direitos e obrigações que procuravam inculcar nos membros de um determinado grupo: "patriotismo", "lealdade", "dever", "as regras do jogo”, “o espírito escolar”, e assim por diante. (p. 19)

Em face dessas afirmativas levantamos a seguinte questão: em que medida pensamos o ballet, o carnaval e as danças folclóricas como manifestações tradicio- nais? Da tradição de que povo? Poderiam ser compreendidos como "tradição inventada"?

\section{Como surgiu o ballet}

A literatura sobre o ballet aponta seu surgimento na Itália, na Idade Média, das grandes procissões do teatro popular religioso e de uma dança grupal chamada "mourisca". Como "mourisco" significava um mouro convertido ao catolicismo, a encenação apresentava dois grupos de homens enfileirados em lados opostos, trajando roupas ornadas com guizos, alguns pintados de preto e que, armados de paus, simulavam a luta de espadas entre mouros e cristãos. Quanto aos elementos que a compunham, constava o bufão portando um símbolo fálico, o homem travestido de mulher, além do uso de castanholas e taconeios, evidenciando sua influência ibérica.

Entre os séculos XIV e XV constata-se uma releitura dessas procissões, adotadas pela casta emergente que, para legitimar sua hegemonia, reproduzia o ritual praticado pelos imperadores da Roma Antiga, ao encenar impressionantes desfiles que simbolizavam o retorno triunfal dos campos de batalha. Chamadas, inicialmente, de Trionphi (triunfos), essas manifestações tinham lugar nas ruas: era o ballo (grande baile), onde os participantes percorriam as ruas da cidade a pé, conduzindo alegorias sobre rodas, o que não tardou muito a ser levado às mansões da aristocracia. Assim, tendo seu espaço de encenação limitado, mesmo apresentando idêntica suntuosidade, adquiriu o nome de balletto ou ballet, o pequeno baile, a exemplo do que fora realizado em 1337, apresentado por Carlos V, da França, a Carlos IV, da Alemanha:

[...] dois carros ricamente adornados que eram conduzidos à mesa do banquete: um representava Jerusalém e conduzia os sarracenos; o outro, uma galera, trazia os soldados cristãos de Godofredo de Bouillon. De forma estilizada tinha lugar um combate que terminava com o triunfo dos cruzados, sendo, os oponentes, banidos da cidade. (Caminada,1999, p. 86)

Nesses espetáculos, Caminada e outros historiadores $^{2}$ apontam a mourisca como a primeira dança ou entrée - dos balletti, base de várias danças populares brasileiras, de manifestações que fazem parte de nosso mais autêntico folclore, como a "chegança", a "cavalhada", praticadas em diversas regiões do Brasil. No amalgamado dessas manifestações, então, transparece a existência de um primeiro elo do Brasil com a dança acadêmica - termo sinônimo de ballet, em vista da 
sistematização e codificação de sua técnica, estruturada e desenvolvida na Academie Royal de Musique et Danse, fundada pelo rei Luís XIV, entre 1669 e 1672.

Adolfo Salazar (1962, p. 69), que tão bem se ocupou da historia da dança e do ballet, também estabelece uma ligação entre as festas medievais, o ballo e o carnaval:

Vêem à superfície costumes ligados que, como as festas romanas e o Carnaval, persistentes durante toda a Idade Média, vão adquirir novo apogeu; solidariamente o aspecto plástico e decorativo do Teatro Religioso Medieval, tão usado desde o século XIII nas festividades do Corpus Christi, adquire um predomínio singular e converte-se em pouco menos que razão de estado. Primeiramente os carros, os arcos triunfais, os desfiles e cortejos a cavalo ou a pé, de dia e de noite, à luz de fachos fumegantes, com os rostos ocultos sob a hipocrisia libertina das máscaras - il travestimento - que a Idade Média já conhecia nas suas momeries, festas de momices que deram origem a todo gênero literário; depois o ballo, que tanta riqueza suntuosa adquirirão nos salões.

Parece correto dizer que estamos falando de festas religiosas, de ballet, de carnaval, da apropriação da dança para determinados propósitos. Parece-nos igualmente correto dizer que o ballet surgiu no continente americano como parte de um projeto ibérico de colonização do Novo Mundo, fosse associado à Igreja e sua necessidade de expansão, fosse como veículo de refinamento para a nobreza e para a constituição de monarquias absolutistas, formadora dos Estados Modernos (Monteiro, 1999). Estamos, assim, tratando da nossa própria colonização.

\section{A origem de algumas danças folclóricas brasileiras}

As primeiras tentativas de colonização dos nativos da Terra de Santa Cruz deixaram claro para os portugueses a necessidade da educação jesuítica, a fim de mostrar aos indígenas os valores da nova civilização. Temos conhecimento de várias apresentações de grupos de meninos índios e portugueses em procissões de características religiosas e profanas, em festas que procuravam aproximar as diversidades étnicas e socioculturais da Colônia (Sucena, 1981, p. 26) e talvez não fossem mais do que a imposição europeia da religião católica, mas a semente de um diálogo híbrido entre as culturas que aqui conviviam.

Ferreira (2004, p. 147) cita que, em 1583, o padre-geral dos jesuítas e o governador-geral Salvador de Sá organizaram uma festa em honra a São Sebastião, na qual meninos índios cantavam e dançavam, encenando um combate e uma procissão. Também Sucena (1981, p. 27) registra diversas festas religiosas, bodas, eventos comemorativos, dentre eles um "triunfo eucarístico" do ano de 1733, "como se aproximando, guardadas as devidas proporções, do balé dos nossos dias".

Assim, as danças mouriscas que nos chegaram da Europa - e que constituíam a primeira entrada do espetáculo renascentista chamado ballet - tornaram-se obrigatórias nas nossas manifestações populares. Mesmo transformadas, guardaram traços bastante evidentes de sua origem nobre - como as antigas contradanças, ${ }^{3}$ quadrilhas e demais danças das cortes europeias -, instituindo nossa tradição. É interessante mencionar ainda a riqueza que a influência africana conferiu às nossas danças: remetendo aos terreiros africanos, algumas incluíram movimentos ondulantes do tronco, ombros e pélvis; outras, de cunho religioso, dispunham os pares em duas filas - como as mouriscas -, representando, como a procissão de São Gonçalo, a corte do rei do Congo (Ferreira, 2004, p. 151).

Nesse ponto cabe mencionar que o ballet tem sido ao longo de décadas apontado como dança europeia que nada tem a ver com a nossa tradição. Para acatar tal premissa, temos de partir do conceito de tradição, pois, curiosamente, nem o carnaval nem as danças populares brasileiras sofrem tal questionamento, sendo reconhecidos por todos como genuinamente nacionais.

\section{Dos triunfos romanos ao carnaval}

O carnaval também inicia sua história com os “triunfos". Em 604, o papa Gregório I determinou que, em certo período do ano, os fiéis deveriam deixar de lado a vida cotidiana para tratar do espírito, jejuando por quarenta dias, em remissão às privações

3. De origem inglesa, a contradança - countrydance, o mesmo que o longway inglês - é de origem popular e não da Corte, apesar de ter sido introduzida na França no fim do século XVII, quando os grandes maestros de dança apropriavam-se de danças populares, faziam adaptações coreográficas e introduziam-nas nos salões, com novos arranjos musicais, adequados aos instrumentos eruditos. No Brasil, o termo "contradança" permaneceu principalmente no sul de Minas e no Rio Grande do Sul, designando um tipo de dança campestre, de pares dispostos em fila. Mas, nos salões do século XIX, tudo indica que a popular/aristocrática contradança inglesa, posteriormente a aristocrática contredanse francesa, se chamou quadrilha (Caminada, 1999, p. 112). 
passadas pelo Cristo, no deserto. A data para o início desse período só foi marcada posteriormente, em 1091, sendo o primeiro dos quarenta dias chamado Quarta-Feira de Cinzas, pelo costume de os fiéis assinalarem, com cinzas, uma cruz na testa em sinal de penitência. Com o passar do tempo, os fiéis aproveitavam os dias anteriores ao jejum para se dedicarem às festas e à comida farta - principalmente à carne, alimento muito consumido no frio europeu. Assim, os dias de fartura antes da quarentena começaram a ser chamados, em italiano, de carne vale (carnevale, "adeus à carne") (Ferreira, 2004, p. 25-26).

Em pouco tempo, a cultura renascentista percebeu que essa festa era um bom momento para aproximar a aristocracia do povo. Nas cidades da Toscana, o carnaval transformou-se no principal evento anterior à Quaresma, onde "acabou-se aprimorando um tipo de festejo peculiar chamado 'triunfo' [...] inspirado nos desfiles triunfais dos imperadores romanos" (Ferreira, 2004, p. 41), como já mencionado anteriormente. Logo, partilhando a mesma origem, o ballet e o carnaval foram igualmente afastados da espontaneidade popular. O ballet, surgido nas ruas italianas, na espontaneidade das manifestações populares, viu seus gestos serem adequados à rigidez dos modos aristocráticos, para quem saltitos e meneios dos quadris não eram bem vistos. Por sua vez, o carnaval tornou-se "mais próximo de uma representação teatral do que de algo que possa ser chamado verdadeiramente de festa carnavalesca", cada vez mais ritualizado e afastado da origem popular (Ferreira, 2004, p. 46).

No século XIX, a burguesia parisiense apropriou-se do modelo dos "triunfos", ocupando as principais ruas da cidade em desfiles sobre carruagens e carros puxados a cavalo. Isto representava não só marcar sua dominação sobre as áreas urbanas, mas também manter certo congraçamento com a população.

No Brasil, simultaneamente, os jogos do entrudo - herança recebida dos portugueses, brincadeira que incluía o derramar de líquidos sobre os transeuntes simulavam também, em seus folguedos, "o batismo de um rei mouro e uma espécie de cavalhada entre mouros e cristãos" (Ferreira, 2004, p. 80), novamente remetendo à mourisca, às procissões do teatro medieval religioso, à origem do ballet.

Festas populares, ritos, cultos, manifestações carnavalescas são reflexos de um mesmo aspecto do mundo onde, segundo Bakhtin (2008, p.16), se vive "o mundo ao avesso", a inversão da ordem social no verdadeiro encontro com os desejos cerceados em que, dentro de uma aparente desordem, se questiona a "ordem" pretensamente verdadeira. A isso Bakhtin chamou "carnavalização": não apenas uma prática social específica, mas a preservação do rito e da festividade popular marcada pela transgressão simbólica do poder estabelecido, que valoriza o inusitado, elimi- nando as barreiras entre o espectador e o espetáculo, tal como os ideais do homem romântico.

Transpondo a carnavalização de Bakhtin para o carnaval carioca de hoje e pensando nos "triunfos" que originaram ballet e carnaval, percebemos traços idênticos nas escolas de samba: carros alegóricos, a simbologia das representações, dramatizações acompanhadas de música e percussão, a sucessão de grupos - as alas -, cada qual apresentando uma dança diferente. Observamos igualmente a reversão nas representações, a sátira ao sério ou sagrado, a exploração da visão hiperbólica, a imposição do profano no confronto entre liberdade de exposição e coisificação do corpo, principalmente o feminino. Finalmente, o casal de mestre-sala e porta-bandeira, vestidos à maneira da Corte, executa uma dança codificada, visivelmente influenciada pelo minueto e pela contradança que a originou.

\section{Ballet e carnaval - próximos ou antagônicos?}

Conforme foi visto, há uma origem comum entre algumas de nossas danças folclóricas, o ballet e o carnaval. Sendo assim, em que momento essas manifestações se aproximam e quando se afastam? Para essa reflexão é interessante recorrer às concepções de Nietzsche em $A$ origem da tragédia (s.d.), nas quais o filósofo sustenta que os estados apolíneos e dionisíacos, em sua dualidade e confronto, engendram a arte.

Conta-nos a mitologia que Apolo e Dionísio eram filhos de Zeus. Apolo foi identificado com o sol, com a verdade, com a beleza, com a música, com a poesia e com as artes em geral, dentre outros domínios. Se, ao nascer, Apolo trouxe a luz de Zeus, perpetuando-a, cabe entender por luz também as ideias, a mente, o poder de criação, a clarividência. Apolo é a tranquilidade do conhecimento ordenador, a lucidez, a preservação dos limites.

De atributos psicológicos diametralmente opostos, Dionísio, forma grega do deus Baco, contrasta com Apolo: é o deus da desordem, do entusiasmo, da exuberância, da brincadeira, do êxtase com os prazeres mundanos - séria ameaça à elite hegemônica da polis. Profano e teatral, representa as forças telúricas do corpo e do inconsciente, a quebra de barreiras entre o homem e a natureza, impostas pela tradição e por convenções. Foi o descobridor da vinha e do vinho, bebida que embriaga, liberta tensões e aflora desejos. Dionísio é o inverso das relações de poder.

Por meio da mitologia, Nietzsche tenta esclarecer os conflitos da mente humana na dualidade entre o princípio apolíneo da racionalidade e do conscien- 
te, em confronto com o princípio dionisíaco irracional dos desejos, paixões e impulsos guardados no inconsciente dos indivíduos. Para o filósofo, são esses estados estéticos, psicológicos e filosóficos opostos que se impõem como condições necessárias para a arte manifestar-se: Apolo é a luz que não vive sem as sombras dionisíacas; Dionísio precisa dos limites que a polis oferece para expressar a arte, condição essencial de transformação do mundo.

O ideal apolíneo alia-se ao ideal renascentista. Apolo nos trouxe a idealização de beleza masculina cuja concepção deveria ser buscada no próprio homem. Para os gregos, a beleza do corpo não era apenas resultado de proporções corretas entre as partes, mas de uma postura corporal específica. Por meio de esculturas e pinturas. É possível perceber, na colocação plástica do corpo no espaço, que noções de posições utilizadas no ballet (como éffacé, croisé etc.) eram comuns aos gregos da Antiguidade. Diríamos então que a dança de Apolo é elitista, cultivada fora das camadas populares, sistematizada, remetendo ao pensamento e à estética do ballet.

Entretanto, para Portinari (1989, p. 26), “o deus mais envolvido em dança é Dionísio”, levado à Roma pagã para presidir as festas ritualizadas nos cortejos de grandes carros alegóricos, com homens e mulheres nus, que cantavam canções obscenas, todos delirando com os prazeres da carne. Assim, "da mitologia greco-romana, e com o nome de Momo, o deus teria migrado para a era cristã, dando origem aos carnavais de Veneza e Turim"; no Brasil, a partir de 1933, o rei Momo começa a reinar,

quando jornalistas de $A$ Noite resolveram dar forma física à personagem, que nasceu como um boneco de enorme barriga e coroa de lata ornando sua cabeça", mais tarde representado por um homem gordo e bonachão que encarnava o boneco-personagem. (Pinheiro,1995, p. 63)

Assim, a dança europeia chamada ballet, trazida para o Brasil como trunfo cultural importante à modernidade e civilização, importada para sustentação das cortes ultramarinas, seria apolínea, enquanto a dança de Dionísio, primitiva, de cor local, intuitiva, indígena, africana, seria dionisíaca? O ballet seria sagrado e o carnaval, profano?

\section{Modernização, europeização - civilizando o Brasil}

Na dualidade inerente à condição humana, Apolo e Dionísio se entrecruzavam em ruas, praças, templos e teatros cariocas dos oitocentos, espaços comuns divididos entre lundus, scottichs, batuques, polkas, ballets, onde vários estamentos e grupos étnicos do Brasil Colônia se reuniam para comemorar alguma data ou reverenciar algum nobre. A dança praticada na época foi tão multifacetada em relação à própria sociedade carioca, entrecruzando-se em um ambiente diverso e difuso quanto a hábitos e costumes, onde tudo que não se enquadrava às regras da aristocracia estava sujeito a sanções preconceituosas. ${ }^{4}$ Mas, de forma estratégica, esses encontros de todos serviam, mesmo que momentaneamente, para atenuar as diferenças sociais.

Vejamos um exemplo. No ano de 1851, em Recife, no recém-inaugurado Teatro Santa Isabel, Maria Baderna, a emblemática bailarina italiana que chegou como estrela ao Rio de Janeiro, em 1849, protagonizou um escândalo ao encenar um lundu, após ter alcançado enorme sucesso em O lago das fadas. Isso porque algumas danças brasileiras eram consideradas pela sociedade e a imprensa em geral, como libidinosas. ${ }^{5}$ Baderna dançou junto com os "grupos do povo", o Lundum d'Amarroa, anunciado como "um gracioso bailado, eufemismo para não assustar a sensibilidade de um certo público" e, posteriormente, dançou Negri, "de título inequívoco", ainda em Recife (Corvisieri, 2001, p. 125-128). Para as autoridades e a elite, ao assumir o lundu, dança de negros e escravos, Baderna punha em risco o processo "europeizador" de anos de tentativas de purificar a raça. Por essa razão, a bailarina, apoiada por seus seguidores, jovens românticos defensores da cultura nacional, tornou-se símbolo do inconformismo.

Preservar a cultura africana ou indígena, assim como impor por meios diversos a cultura europeia, era uma articulação difícil mas viável, uma vez que, ao mesmo tempo se preservava uma e se absorvia outra, evidenciando dois territórios onde a delimitação, gradativamente, ia-se atenuando. Era como se Apolo e Dionísio começassem a dividir espaços comuns; seria o caso de pensar a chegada de um mundo apolíneo em domínios dionisíacos.

\footnotetext{
4. Nesse ponto, cabe notar que, se os habitantes da cidade tiveram de conviver com práticas cortesãs, a corte recém-chegada, em 1808, igualmente conheceu uma cidade que passava a aglutinar três sociedades: uma nativa, outra africana - escravizada - e uma última, branca, europeia e católica, dos europeus que aqui chegaram. Em textos de diversos historiadores e viajantes europeus que aqui estiveram, percebe-se que tudo aquilo que escapava ao refinamento europeu era visto com espanto e desaprovação.

5. Em artigo publicado no Diário de Pernambuco, em 28 de janeiro de 1851, o autor anônimo se contrapõe à reação de alguns segmentos perguntando "qual o passo, qual o bamboleio, o rebolado lascivo do lundu que poderia ser comparado aos trechos em que a delicada Baderna, leve como uma sílfide, abre as pernas como se desejasse se dividir em duas?". Para ele, a justificativa talvez fosse por serem "danças nacionais e não estrangeiras" (Corvisieri, 2001, p.124).
} 
Nesse ponto, cabe avaliar o teatro de revista ${ }^{6}$ e os cassinos, talvez como pioneiros do diálogo efetivo entre o popular e o erudito, como espaço de experimentações cênicas, de quebra de barreiras entre classes e formação de identidades. A revista, cujo apogeu consolidou-se no Brasil entre as décadas de 1880 e 1940 (Pereira, 2003, p. 162-169), ao adotar a linguagem coloquial nas cenas até então marcadas pelo estilo lusitano, além de utilizar a música popular - e mais tarde a de carnaval -, proporcionava em seus enredos um diálogo claro entre as duas culturas. O teatro de revista permitiu um novo olhar sobre o corpo na miscigenação de linguagens, em que

o mesmo maxixe e depois o samba deveria se dissolver num corpo treinado pela técnica do balé. $\mathrm{Ou}$ vice-versa. Se, a partir disso, a estilização das danças nacionais acaba sendo, por um lado, um único caminho possível, quando executada por um bailarino, por outro, foi com o ensino do balé em terras brasileiras que se pôde dispor melhor cenicamente as revistas em termos coreográficos. (Pereira, 2003, p. 172)

Trazendo a discussão aos nossos dias para analisarmos as escolas de samba - em tese, dionisíacas enquanto espetáculo -, observamos que, curiosamente, elas se afinam com o princípio apolíneo. "Em vez de desmantelarem a ideologia do poder, repetem, em sua linguagem, a ordem e a estrutura vigente, [...], nos dando uma exemplar lição de disciplina radical" (Pinheiro, 1995, p. 117) e perseguindo quase sempre os critérios apolíneos de sofisticação, luxo e riqueza.

Assim é que, ao logo dos anos, tanto no aspecto técnico quanto artístico, os desfiles das escolas de samba foram assimilando uma estrutura que vem se aprimorando através de profissionais formados principalmente na dança sistematizada e nas artes plásticas, encarregados de acompanhar o gigantismo e a espetacularização dos desfiles atuais. Esses profissionais buscam, no seu conhecimento técnico/artístico e nas concepções dos espetáculos trazidos dos palcos tradicionais, as maneiras mais variadas e criativas de promover a harmonia entre a diversidade cultural dentro do carnaval.

Um exemplo clássico desse diálogo entre o popular e o erudito aconteceu no carnaval de 1963, durante o desfile do Salgueiro com o enredo "Chica da Silva: a feiticeira de Araxá", no qual Mercedes Baptista ${ }^{7}$ apresentou um minueto, remetendo à dança dos salões da sociedade de Diamantina que a negra Chica passara a frequentar após seu casamento. A coreografia, inimaginável para a época, trazia bailarinos pertencentes ao Corpo de Baile do Teatro Municipal e jovens do morro do Salgueiro, doze casais vestidos como nobres da corte barroca que dividiram a opinião da plateia: enquanto alguns acreditavam estar ali a inovação do carnaval, ${ }^{8}$ outros temiam pela descaracterização da festa popular (Silva Junior, 2007, p. 71).

A polêmica em torno da "preservação da tradição" perdura até os dias de hoje, migrando para outros segmentos, como a comissão de frente, grupo que abre o desfile de cada agremiação, um dos quesitos que sofreu as mais expressivas alterações nas últimas décadas. Atualmente a maioria das escolas, tanto as do chamado grupo especial (a elite) quanto as do grupo A, utiliza bailarinos(as) profissionais em suas comissões. ${ }^{9}$

Com relação ao mestre-sala e à porta-bandeira, o bailado busca, dentro de uma forma específica de sensibilidade, apresentar o jogo de conquista e sedução que, em última instância, é o que tem de tradicional.

A porta-bandeira e o mestre-sala, desse modo, são exemplos da formulação de uma ideia de 'tradição' e de compreensão da duração temporal, esteticamente expressa no desfile, definindo situações e organizando um sistema carnavalesco mais amplo que quer permanecer. Nesse eixo de análise, os aspectos múltiplos e vigorosos da "tradição" de sua dança são atualizados por meio de determinadas "experiências". Nelas, a criatividade não deve ser buscada de modo a

6. Autêntico teatro de costumes, a revista chegou ao Brasil em 1859, mas sua história remete ao século XVI, ao nascimento da Commedia dell'Arte, nas ruas de Veneza e à instauração das primeiras companhias profissionais de teatro. Opondo-se ao fausto renascentista, no início de 1700, o grupo de artistas italianos levava esses espetáculos para as feiras parisienses (Veneziano, 1991). Misturando vaudeville e opereta, a afrancesada revue de fin d'année fazia a revisão de fatos ocorridos nos doze meses próximos passados, inicialmente de forma burlesca, mas logo acrescida da crítica política e da de costumes - o teatro de costumes -, cuja revisão de fatos e fantasias a caracterizou e definiu como teatro de revista.

7. Mercedes Baptista, a primeira bailarina negra do Teatro Municipal do Rio de Janeiro, foi também pioneira em levar a experiência trazida dos palcos tradicionais para a avenida.

8. Segundo Fernando Pamplona (apud Silva Júnior, 2007, p. 74), a introdução do "passo marcado" já havia sido feita na década de 1960, tanto no Império Serrano quanto na Mangueira, antes de Mercedes Baptista.

9. No desfile de 2009, das doze escolas que compunham o grupo especial, todos os coreógrafos das Comissões eram bailarinos. Entre os clássicos: João Wlamir (Império Serrano), Hélio Bejani (Salgueiro) Rodrigo Negri (Unidos da Tijuca), Sergio Lobato (Unidos do Viradouro), Gislaine Cavalcanti (Beija Flor de Nilópolis), Marcelo Misailidis (Vila Isabel), Jorge Texera (Portela) e Janice Botelho (Mangueira). Entre os profissionais do jazz/dança contemporânea: Renato Vieira (Grande Rio), Fabio de Mello (Mocidade Independente de Padre Miguel), Regina Sauer (Unidos do Porto da Pedra) e Alex Neoral (Imperatriz Leopoldinense). 
surpreender como novos suportes, roupas ou performances. O bailado não tem interesse em romper com a tradição, porque a criatividade não prevê a mudança. O bailado e o repertório de gestos tradicionais são compreendidos sempre dentro e nunca fora da rede de sentidos do próprio desfile. Manter essa criatividade conservadora - papel desempenhado pelo casal de nobres que leva importante símbolo da escola - no rito em que prevalece a ideologia de uma criatividade transformadora traz importantes consequências. (Cavalcanti; Gonçalves, 2009, p. 242)

Mas, tradicionais ou não, apolíneas ou dionisíacas, as cores acentuadas pelos contrastes e pelos excessos indicativos da festa burlesca, atuam como um grande catalisador: se na década de 1940, Madeleine Rosay $^{10}$ já buscava uma brasilidade genuína dançando nas pontas dos pés o "Tico-tico no Fubá" e Mercedes, nos anos 60 punha o minueto "na avenida", hoje encontramos a apolínea (?) Ana Botafogo sambando sobre as pontas dos pés em dupla com o dançarino/passista dionisíaco (?) Carlinhos de Jesus, no casamento entre erudito e popular. $\mathrm{Na}$ verdade, o que temos é a dissolução de fronteiras entre a arte e o mundo, entre o sagrado e o profano, entre o sublime e o grotesco, entre Apolo e Dionísio.

\section{Considerações finais}

É senso comum afirmar que o gestual foi a primeira forma de comunicação do homem, e a dança, essencialmente grupal, sua primeira forma de expressão. O tempo passou e a função dessa dança mudou. Melhor dizendo, diversificou-se e enriqueceu.
Assim é que se pode observar hoje, no universo da dança, uma gama de manifestações estéticas, sistematizadas ou não, à moda brasileira ou mais sintonizadas com os estilos internacionais. Convivem, junto, expressões folclóricas, populares, danças da moda que se divulgam, popularizam e são consumidas através dos veículos de comunicação de massa, até serem substituídas no tempo estabelecido pela mídia. Acreditamos que o ballet e o carnaval de hoje são fruto do entrelaçamento de várias culturas e que cada uma delas lhes confere peculiaridades; é esse hibridismo cultural que os enriquecem, acrescentam, atualizam. Mantendo a tradição - ou supondo-se tradicional -, toda manifestação, a partir de sua saída do local de origem, passa a ser importada pelo grupo que a recebe, assimila, adota, permitindo-se colorir com outras nuances. O Brasil possui a tão propalada mistura de raças, culturas e etnias, do mesmo modo que, na Europa ocidental, não existe nenhuma nação formada apenas de um único povo, cultura ou etnia.

Ao nos referirmos, anteriormente, à influência ibérica presente na mourisca renascentista, estamos registrando o período histórico que marcou nossa colonização, ou seja, esta começa também a ser a nossa história. E constatamos que foram as mouriscas que serviram tanto de base ao ballet quanto às nossas manifestações consideradas mais autênticas, como o carnaval, vários de nossos folguedos e danças populares.

Assim, a herança das grandes procissões foi marcadamente adotada pelo Brasil colonial. Ainda que mais de dois séculos depois da Europa, seguimos o mesmo caminho que o continente europeu percorreu, do mesmo modo que um século separou o início do ballet na Itália, de sua entrada na França e nas demais cortes europeias.

10. Madeleine Rosay, do Teatro Municipal do Rio de Janeiro, foi a primeira artista brasileira agraciada com o título de Primeira Bailarina.

\section{Referências}

BAKHTIN, Mikhail. A cultura popular na Idade Média e no Renascimento: o contexto de François Rabelais. Tradução de Yara Frateschi Vieira. 6 ed. São Paulo: Hucitec; Brasília: Ed. UnB, 2008.

CAMINADA, Eliana. História da dança: evolução cultural. Rio de Janeiro: Sprint, 1999.

CAVAlCANTI, Maria Laura; GONÇALVES, Renata (Orgs.). Carnaval em múltiplos planos. Rio de Janeiro: Aeroplano, 2009.

CORVISIERI, Silverio. Maria Baderna: a bailarina de dois mundos. Rio de Janeiro/São Paulo: Record, 2001.

FERREIRA, Felipe. O livro de ouro do carnaval brasileiro.
Rio de Janeiro: Ediouro, 2004.

HALL, Stuart. A identidade cultural na pós-modernidade. Tradução de Tomaz Tadeu da Silva e Guacira Lopes Louro. 10. ed. Rio de Janeiro: DP\&A, 2005.

HOBSBAWM, Eric; RANGER, Terence. A invenção das tradições. 3. ed. Rio de Janeiro: Paz e Terra, 2002.

MONTEIRO, Marianna. Balé, tradição e ruptura. In: PEREIRA, R.; SOTER, S. (Orgs). Lições de dança 1. Rio de Janeiro: UniverCidade Editora, 1999.

NIETZSCHE, Friedrich Wilhelm. A origem da tragédia. São Paulo: Moraes, [s.d.].

PEREIRA, Roberto. A formação do balé brasileiro: naciona- 
lismo e estilização. Rio de Janeiro: Ed. FGV, 2003.

PINHEIRO, Marlene M. Soares. A travessia do avesso: sob o signo do carnaval. São Paulo: Annablume, 1995.

PORTINARI, Maribel. História da dança. Rio de Janeiro:

Nova Fronteira, 1989.

SACHS, Curt. Historia universal de la danza. Buenos Aires: Centurion, 1944.

SALAZAR, Adolfo. História da dança e do ballet. México:

Artis, 1962.
SILVA JÚNIOR, Paulo Melgaço. Mercedes Baptista: a criação da identidade negra na dança. Brasília: Fundação Cultural Palmares, 2007.

SUCENA, Eduardo. A dança teatral do Brasil. Rio de Janeiro: Fundacen, 1981.

VENEZIANO, Neyde. O teatro de revista no Brasil: dramaturgia e convenções. Campinas: Pontes; Ed. Unicamp, 1991.

\title{
Between the popular and the erudite, "Brazilian civilization began with the feet"
}

\begin{abstract}
Although the common sense considers the ballet an imported art, which has no link with our traditions, whereas carnival is our most expressive popular demonstration, the objective of this paper is to show that both kinds of cultural manifestation in question, as well as some typical brazilian folk dances, have the same origin. We observe how ballet dance compositions can present elements known as popular, as well in carnival the choreographic systematization is increasingly growing in the samba schools, where professionals from the arts called erudite engrave academic principles to the popular art. Therefore, we take as starting point the concept of "invented tradition”, proposed by Eric Hobsbawm and Terence Ranger, to investigate how the (re)appropriations among the three artistic expressions occur and how is the coexistence between erudite dance and popular dance nowadays.
\end{abstract}

Key words: Ballet, carnival, typical folk dances, culture, "invented tradition".

\section{Entre el popular y el erudito, "la civilización en Brasil empezó por los pies"}

\section{Resumen}

Aunque el sentido común considere el ballet un arte importado, que no tiene nada que ver con nuestra tradición cultural, mientras el carnaval es nuestra manifestación popular más significativa, el objetivo de ese trabajo es mostrar que los dos géneros culturales en cuestión, así como también algunos bailes folclóricos brasileños, comparten del mismo origen. Observamos como las composiciones coreográficas de los ballets pueden presentar elementos dichos populares, así como, en el carnaval, la sistematización coreográfica es cada vez más practicada en las escuelas de samba, campo donde profesionales oriundos de los artes llamados eruditos imprimen principios académicos al arte popular. Así, tomamos como punto de partida el concepto de la "tradición inventada", propuesto por Eric Hobsbawm y Terence Ranger, para investigar de qué manera ocurren las (re)apropiaciones entre esas tres expresiones artísticas y cómo se da la convivencia entre el baile erudito y el baile popular en los días de hoy.

Palabras clave: ballet, carnaval, bailes folclóricos, cultura, tradición inventada.

Data de recebimento do artigo: 27/6/2010

Data de aprovação do artigo: 29/9/2010 